\title{
MERCADO, COLEÇÕES E INTERCONEXÕES: ALGUMAS PISTAS PARA COMPREENDER TROCAS COMERCIAIS VIA INTERNET
}

\author{
MARKET, COLLECTIONS AND INTERCONNECTIONS: SOME HINTS TO \\ UNDERSTAND COMMERCIAL EXCHANGES VIA THE WEB
}

Débora Krischke Leitão ${ }^{1}$

\section{RESUMO}

O presente artigo parte de pesquisa realizada junto a compradores e vendedores que se relacionam através da Internet. Discutimos as trocas comerciais ali estabelecidas, oferecendo um contraponto à imagem de impessoalidade e instrumentalidade comumente atribuída à troca monetarizada. Procuramos mostrar o papel da honra e da confiança baseada na reputação para o grupo estudado, apontando relações que ultrapassam a mera circulação de dinheiro e mercadorias. Sublinhando a forte presença de colecionadores envolvidos em tais trocas, trazemos, igualmente, algumas reflexões sobre consumo e colecionismo, importantes para a compreensão das relações entre sujeitos e objetos no mundo contemporâneo.

Palavras-chave: Internet. Trocas comerciais. Colecionismo.

\footnotetext{
${ }^{1}$ Departamento de Antropologia, Universidade Federal de Mato Grosso.
} 


\section{ABSTRACT}

This article starts from a research with buyers and sellers who interact over the web. We discuss the commercial exchanges established there, offering an opposition to the image of impersonality and instrumentality commonly attributed to monetized exchange. We intend to show the role of honor and trust based on reputation to the group studied, pointing out relationships that go beyond the mere circulation of money and goods. Underlining the strong presence of collectors involved in such exchanges we bring, as well, some reflections about consumption and collectionism, important to understand the relations between subjects and objects in the contemporary world.

Keywords: Internet. Commercial exchanges. Collectionism.

People, machines and money matter in this world, in that order. (HART, 2004, p. 16).

Muito embora a Internet já tenha sido objeto de reflexão de um número razoável de autores, a maioria das obras produzidas sobre o tema partiu de uma perspectiva exclusivamente teórica e excessivamente generalizadora. Na contramão de tal produção, vemos o desenvolvimento recente, no Brasil e alhures, de pesquisas etnográficas que se preocupam em compreender os usos particulares que são feitos da Internet por grupos específicos, as formas de sociabilidade desenvolvidas no ambiente do ciberespaço e as interações entre sujeitos mediadas pelas novas tecnologias comunicacionais.

A Internet chega ao Brasil no final da década de 1980, restrita, nesse momento inicial, a uma conexão internacional de redes acadêmicas. A rede tornou-se aberta no país a partir de 1994, com o surgimento dos primeiros provedores de acesso. Com a rede aberta, World Wide Web (WWW), o usuário deixou de ser o "técnico especializado em computação e passava a ser todo e qualquer cidadão interessado em informar-se, vasculhar a rede, ou trazer conteúdo próprio, contribuindo para sua expansão". (GETSCHKO, 2009, p. 50).

A pesquisa nacional por amostra de domicílios, conduzida pelo Instituto Brasileiro de Geografia e Estatística (IBGE, 2005) indica que o percentual de domicílios com microcomputadores era, no Brasil, de $18,6 \%$, dos quais $73,6 \%$ possuíam acesso à Internet. Atualmente, de acordo com pesquisas elaboradas pelo Comitê Gestor da Internet no Brasil (2009), chegamos à marca de 60 milhões de usuários de computador no país, e 54 milhões de usuários de Internet. Em 2005, ainda de acordo com o mesmo órgão, o percentual de domicílios com acesso à Internet era de $13 \%$, tendo crescido, em 2008 , para cerca de $20 \%$.

Podemos dizer que a infiltração do comércio no ciberespaço aconteceu desde os primórdios da Web. Ainda no início dos anos de 1990, as primeiras empresas que abriram suas filiais virtuais de e-comércio voltavam-se para os negócios de atacado, fornecendo online produtos para seus revendedores nas mais diversas partes do globo (CASTELLS, 2003), num tipo de transação comercial denominada B2B (business to business). Apenas alguns anos depois, vimos o surgimento dos primeiros sites dedicados ao comércio $\mathrm{B} 2 \mathrm{C}$ (business to consummer) que, na mesma direção do capitalismo contemporâneo, se caracterizou, de acordo com Lévy (2001), pela criação de grandes conglomerados transnacionais, espécies de supermercados virtuais, a exemplo da livraria virtual Amazon. Em outros casos, redes de lojas já existentes expandiram suas atividades para a Internet visando abarcar um leque de consumidores além de suas fronteiras geográficas.

Tendo em vista do grande número de trocas comerciais realizadas contemporaneamente via Internet e os debates propostos por antropólogos que estudam o/no cyberespaço sobre 
sociabilidade na Internet e interação entre sujeitos mediadas pelo computador, iniciamos, em agosto de 2008, uma pesquisa sobre relações de consumo na Internet, ${ }^{2}$ chegando a uma agregação eletrônica denominada Mercado Livre. Tomando como foco principal de análise o site em questão, realizamos observação participante na interface e entrevistas, via Internet e face a face, com vendedores e compradores, percorrendo redes de relações estabelecidas entre os usuários.

Ainda que as atividades comerciais predominantes na rede sejam aquelas nomeadas anterioremente como business to business e business to consummer, o tipo de transação que estudamos diferencia-se de ambas. Chamada por seus usuários de transação P2P (peer to peer), embora faça uso de uma plataforma desenvolvida por uma empresa, diz respeito a trocas diretas estabelecidas entre pessoas. O significado do termo utilizado, peer, é digno de nota: pessoa que é igual a outra em categoria, status ou mérito. Trata-se, portanto, de uma transação que é imaginada não apenas como relação "de pessoa para pessoa", mas "entre iguais". Assim, teríamos a presença de uma alternativa às relações comerciais hegemônicas, já que realizada entre parceiros que se situam em posições equivalentes.

Inspirado no site de leilões norte-americano Ebay, criado em 1995, o Mercado Livre iniciou suas atividades no Brasil e na Argentina em 1999, rapidamente espalhando-se por outros países latino-americanos. Nos 12 países onde atua atualmente, o Mercado Livre conta com 33,7 milhões de usuários cadastrados a as trocas comerciais ali realizadas totalizaram, em 2008, um valor de 2,8 bilhões de dólares. ${ }^{3}$

Ao contrário de outras empresas atuantes no mercado de consumo via Internet, o Mercado Livre não é uma loja ou shopping virtual. Trata-se de uma plataforma de compra e venda que serve como mediadora para transações realizadas entre compradores e vendedores individuais, mantida através de comissões pagas pelos vendedores e de uso gratuito para compradores. A transações comerciais ali acontecem sob forma de leilão (com lance livre ou obedecendo a um lance mínimo estabelecido pelo vendedor) ou, em alguns casos, compra direta.

\section{MERCADO E TROCAS COMERCIAIS}

A partir da teoria geral da troca proposta por Mauss (2003) e da análise do Kula enquanto cerne da vida social trobriandesa (MALINOWSKI, 1978), registra-se a presença quase transversal da problemática da troca no pensamento antropológico. Mauss, recorrendo a dados etnográficos - obtidos por diversos antropólogos, entre eles Malinowski e Boas - e a alguns códigos de direito antigos, procura mostrar-nos como as trocas em muitas sociedades ultrapassam a esfera jurídica e econômica, apresentando-as como fato social total: múltiplas dimensões (religiosa, política, econômica, entre outras) são contempladas e diferentes conjuntos de tipos da atividade social a partir delas se estabelecem.

Fazendo uso do termo "dons recíprocos", 4 Mauss (2003, p. 191) propõe que olhemos para a troca procurando ver para além dos objetos que são trocados, pois seu fundamento não estaria neles, mas no laço criado a partir de sua circulação:

\footnotetext{
2 Projeto de pesquisa "Consumo, estilos de vida e sociabilidade on e off line", desenvolvido junto à Universidade Federal de Mato Grosso, com a participação da bolsista PIBIC/CNPQ Daiane Renner.

${ }^{3}$ Fonte: www.mercadolivre.com.br

${ }^{4}$ Como adverte Sigaud (1999), o termo reciprocidade não aparece no autor, sendo a teoria da reciprocidade um desdobramento lévi-straussiano do princípio, descrito por Mauss, da dádiva fundada no tripé darreceber-retribuir.
} 
Nas economias e dos direitos que precederam os nossos, nunca se constatam, por assim dizer, simples trocas de bens, de riquezas e de produtos num mercado estabelecido entre os indivíduos. [...] o que eles trocam não são exclusivamente bens e riqueza, bens móveis e imóveis, coisas úteis economicamente. São antes de tudo, amabilidades, banquetes, riquezas, serviços militares, mulheres, crianças, danças, festas, feiras, dos quase o mercado é apenas um dos momentos, e nos quais a circulação de riquezas não é senão um dos termos de um contrato bem mais geral e bem mais permanente.

Ainda que a troca, entendida enquanto indispensável à vida social, seja anterior e situese para além do sistema capitalista, é certo que, no contexto histórico específico da economia de mercado ocidental que tomou forma a partir do século XVIII, a circulação de mercadorias adquira certas nuanças particulares. De acordo com o autor, "[...] a história e a etnografia conhecem várias espécies de economia, a maioria delas incluindo a instituição do mercado, mas elas não conhecem nenhuma economia anterior à nossa que seja controlada e regulada por mercados, mesmo aproximadamente". (POLANYI, 2000, p. 63).

Uma economia de mercado seria um sistema econômico regulado por mercados, fenômeno surgido no final do século XVIII e que pressupõe uma separação entre esfera econômica e política. Sua grande especificidade, segundo Polanyi (2000), seria a disjunção entre motivação econômica e relações sociais, já que todas as configurações anteriores, ainda que pudessem incluir a figura do mercado, tinham suas relações econômicas combinadas com os princípios identificados pelo autor como reciprocidade, redistribuição e domesticidade.

Mas se, para Polanyi (2000), a utilização do dinheiro não caracteriza por si só a especificidade da economia de mercado, este ocupa papel central na reflexão de Simmel (2004). Tratando igualmente das singularidades das relações sociais que se estabelecem no cenário da "economia monetária madura", Simmel (2004) discorre sobre o papel do dinheiro, seu significado social e as consequências de sua onipresença nas relações de troca.

De acordo com Simmel (2004), o dinheiro permite certa flexibilidade aliada à objetividade nas trocas de mercadorias, servindo enquanto "peso e medida" de padronização do valor dos bens. Por outro lado, ele instaura relações comerciais impessoais e instrumentais. Se as relações comerciais nos mercados de outrora, tão bem descritos por Braudel (1996), se fundavam em laços mais estreitos e eram "pessoalizadas", frequentemente garantidas através da confiança, da reputação, da honra e da "palavra"; na economia monetária moderna, as trocas comerciais, mediadas pelo dinheiro, tornam-se mais institucionalizadas, anônimas e individualizantes. Simmel (1979) sugere ainda que as formas monetárias de troca fazem parte de um conjunto de novos padrões de vida, instaurados, sobretudo, com a industrialização e a urbanização, que reordenam as relações sociais, todas elas igualmente baseadas na impessoalidade e na razão instrumental.

Mesmo que a impessoalidade do dinheiro e das trocas comerciais monetarizadas seja, por vezes, colocada em xeque por autores que analisam as razões simbólicas do econômico, ${ }^{5}$ a literatura antropológica, ${ }^{6}$ lançando mão de exemplos sobre como o dinheiro é representado em

\footnotetext{
${ }^{5}$ Cf. Zelizer (1997) e Hart (2001).

${ }^{6}$ Cf. Oliven (2001, 1997), Zelizer (1992), Bloch (1994) e Monjaret (1998).
} 
diversas sociedades ocidentais contemporâneas, mostra-nos que, em nosso imaginário, ele pode ser considerado perigosamente "fora de lugar" quando misturado à família, amor, amizade, e outras "vacas sagradas" de nosso tempo.

Todavia, concordando com Slater (2001), acreditamos que um mercado nunca é apenas um lugar de encontro efêmero e instrumental entre vendedores e compradores, e uma primeira aproximação ao fenômeno por nós estudado já permite que pensemos sobre relações de sociabilidade estabelecidas através das relações comerciais ali presentes. Se a sociabilidade dos mercados tradicionais tinha, como diz Braudel (1996), o espaço do burgo como seu cenário privilegiado, e se as trocas monetarizadas, analisadas por Simmel (1979), tinham como cenário a grande metrópole, as relações comerciais entre sujeitos que tem lugar no "espaço virtual" podem estabelecer relações sociais semelhantes aquelas descritas por Lins Ribeiro (1995) como "comunidades imaginadas transnacionais".

\section{SOCIABILIDADE, HONRA E CREDIBILIDADE NAS TROCAS COMERCIAIS VIA INTERNET}

A plataforma Mercado Livre permite que as conversas entre vendedores, compradores e interessados sejam públicas, gerando uma verdadeira rede de troca de informação e compartilhamento de interesses, acrescida igualmente de discussões realizadas em outro espaço do site, este dedicado especialmente a fóruns e listas de discussão sobre vendedores, compradores e avaliação de produtos. Mesmo nas transações do tipo "compra direta" verificamos que a barganha, realizada entre compradores e vendedores via espaço de perguntas e respostas, tem lugar importante nas práticas comerciais. Assim, podemos dizer que, através de relações comerciais mediadas pela Internet, mas realizadas de pessoa para pessoa, o Mercado Livre estabelece uma rede de troca de objetos, ideias e informações.

Além disso, talvez seja possível problematizar o caráter "anônimo" e "impessoal" - atribuído tanto às trocas comerciais contemporâneas quanto ao uso da Internet para fins de interação social - através desse mecanismo de compra e venda que, paradoxalmente, situa-se na imbricação entre comércio e Internet.

Justamente por privilegiar a troca e a relação comercial direta entre sujeitos, a plataforma Mercado Livre adota um sistema de pontuação (conhecida como "qualificação") para medir a credibilidade de seus vendedores e compradores. Após a concretização de uma negociação, as contrapartes classificam-na como "positiva", "negativa" e "neutra", podendo, a seguir, registrar depoimentos sobre seus parceiros e detalhes sobre a interação transcorrida e sobre os objetos adquiridos. Tanto a classificação quanto os depoimentos são públicos e, na grande maioria das vezes, também as informações sobre os produtos anteriormente negociados permanecem disponíveis na plataforma para que seja possível saber não apenas quem comprou de quem, mas igualmente o que foi comprado ou vendido, por qual preço e sob quais condições.

Percorrendo redes de troca comercial estabelecidas no site, percebemos que os vendedores raramente são apenas vendedores, já que, em muitas trocas, também se situam como compradores. Assim, as qualificações recebidas em ambas as posições são utilizadas pelos usuários como uma espécie de cartão de visitas, que apresenta o vendedor/comprador a um novo comprador/vendedor com o qual não há relação anteriormente estabelecida. De modo a oferecer a garantia de quem se é e do que se tem feito nos últimos meses e anos, no espaço do site, alguns usuários optam por referir-se a suas qualificações nos próprios anúncios dos produtos vendidos, seja através de avisos como "mais de cem qualificações positivas, confira e confie", ou reproduzindo no corpo do anúncio as últimas (ou as mais positivas) qualificações recebidas. 
O sistema de credibilidade baseado em qualificações em muito faz lembrar as relações de troca "tradicionais" anteriormente descritas, baseadas na honra e na confiança. Nas palavras de um dos vendedores entrevistados,

A reputação é a única garantia. Posso oferecer um produto de qualidade, um preço convidativo, e não vender. Você só vai comprar de mim se eu apresentar uma garantia de que vou mesmo entregar o que vendo, de que não sou uma fraude. Uma boa reputação é o que garante. Uma boa reputação não se faz do dia para a noite, mas se desfaz do dia para a noite. Você comete um erro e será negativado [receberá uma qualificação negativa], não adianta tentar explicar o que houve, ficará marcado na sua reputação. (Felipe, São Paulo, 792 negociações).

No grupo de usuários por nós pesquisado, também é significativo o número de negociações estabelecidas entre conhecidos. Compra-se, muitas vezes, daqueles de quem já se comprou ou para quem já se vendeu. A primeira negociação é feita às escuras, baseada nas qualificações, mas as seguintes carregam a certeza, baseada na experiência, de que o vendedor/comprador é honesto e confiável. Nesses casos, a negociação feita no espaço destinado as perguntas e respostas torna-se bastante mais pessoal: chama-se o parceiro pelo nome, nem sempre explicitado nos anúncios, já que os usuários fazem uso de pseudônimos, mas conhecido graças às trocas anteriores; elogia-se publicamente o produto anunciado e o próprio vendedor; barganhase preço e prazo; solicitam-se outros produtos não anunciados, mostrando conhecimento a respeito da especialidade do vendedor e do leque de mercadorias daquele gênero disponíveis no mercado.

No que concerne às trocas entre os já parceiros, também a qualificação possui especificidades. Muitas vezes nela o comprador/vendedor faz questão de explicitar o número de transações já realizadas com o outro, utilizando expressões como "mais uma vez uma ótima negociação" ou "excelente, como sempre". Assim, na contramão dos discursos que apontam para o anonimato e a impessoalidade, vemos a importância das relações pessoais e da proximidade com o outro sendo enfatizada e valorizada publicamente nesse tipo de troca.

\section{CONSUMO, TROCA E COMÉRCIO}

Mesmo que a rede de computadores transporte apenas impulsos eletrônicos, e não átomos, acompanhamos a circulação de bens de consumo através de redes sociais estabelecidas no ciberespaço. Nesse sentido, compartilhamos da perspectiva que enfatiza a centralidade do consumo em nossa sociedade. Sahlins (2003), remetendo à Lévi-Strauss, questiona se o operador totêmico não teria sido, em nossa sociedade, substituído por espécies e variedades de objetos manufaturados que, a exemplo das categorias totêmicas, teriam o poder de demarcar e classificar. Como aponta Oliven (2006, p. 7):

É natural que a Antropologia se ocupe da questão do consumo. Afinal, mais do que um fenômeno econômico, o consumo é uma questão cultural e social. Não existe o consumidor isolado. Mesmo quando alguém toma uma decisão individual de adquirir um produto, esse comportamento é condicionado pelo contexto em que os indivíduos vivem e interagem. Os estudos antropológicos sobre o consumo preocupam-se 
em compreendê-lo como fenômeno cultural, procurando mostrar que, junto com uma lógica racional da produção, existe uma lógica simbólica que envolve uma série de fatores, muitas vezes difíceis de compreender à primeira vista.

Embora a relação entre sujeitos e objetos há muito permeie a reflexão antropológica, podemos dizer que é no final da década de 1970, graças à publicação das obras de Sahlins (2003) e Douglas e Isherwood (2004), que surgem os primeiros estudos antropológicos sobre o consumo nas sociedades contemporâneas. ${ }^{7}$ Se, como sugere Sahlins (2003), as Ciências Sociais por muito tempo privilegiaram o domínio da "produção", deixando de lado o consumo de bens, o campo da Antropologia do Consumo, tal qual se estabeleceu na atualidade, tem como objetivo compreender as lógicas culturais e os sistemas simbólicos acionados nas práticas cotidianas de consumo. Assim, diversos autores vão, contemporaneamente, propor uma agenda de pesquisa que, a partir de etnografias sobre hábitos e escolhas de consumo, aponta para a importância dos objetos na costura das relações sociais e na elaboração de processos identitários. ${ }^{8}$

Quando Douglas e Isherwood (2004) sugerem que os bens podem ser compreendidos enquanto "cercas" e "pontes", delimitando grupos através do fortalecimento de pertencimentos e/ou da materialização de exclusões e contrastes, embora tratem do sistema capitalista, encontram respaldo na literatura antropológica clássica sobre troca e reciprocidade. Nesse sentido, convém retomar a reflexão inicial sobre a troca, já que as semelhanças e diferenças entre as trocas comerciais monetarizadas e as trocas recíprocas não monetarizadas, à la Kula, geraram uma série de debates.

Na trilha iniciada por Mauss, Godbout (1998) mostra-nos por quais razões o paradigma da dádiva ${ }^{9}$ é frequentemente visto como antagônico à lógica do mercado. Segundo o autor, o mercado seria um tipo de laço social que visa escapar das obrigações. Ser um indivíduo no mercado é não dever nada a ninguém, ao passo que a dádiva estaria baseada na dívida que é deliberadamente mantida. Edmund Leach (1983), partindo da obra de Malinowski, também se pergunta sobre o antagonismo entre dádiva e mercado, dizendo que tanto as trocas simétricas (uma coisa por outra semelhante) quanto as trocas assimétricas (uma coisa por outra coisa distinta) se dividem em dois tipos: aquelas que são expressivas de relações permanentes e aquelas que têm o efeito de cancelar uma dívida prévia. No último tipo, não há dívida residual - pago ao padeiro um tanto de dinheiro por minha fatia de pão, exemplifica Leach, e não devo mais nada e a transação é completa, ao passo que a relação entre parceiros do Kula é de dívida permanente.

Voltando a Mauss, Caillé (1998), por sua vez, diz que se a dádiva não se enquadra totalmente no paradigma de um utilitarismo econômico - no qual o indivíduo, regido por interesses, funciona segundo uma razão instrumental -, ela tampouco configura um "utilitarismo normativo", no sentido de ser motivada exclusivamente por um respeito incondicional à norma e obrigação de dar exteriormente imposta. $O$ argumento de Caillé é de que, em Mauss, não há o sujeito do holismo - controlado demais por forças macrossociais - e tampouco o indivíduo do individualismo metodológico - livre calculador de custos e benefícios.

\footnotetext{
7 Os livros The World of Goods, de Mary Douglas e Baron Isherwood, e Culture and Practical Reason, de Marshall Sahlins, são contemporâneos, tendo o primeiro sido publicado pela primeira vez em 1979 e o segundo em 1976.

${ }^{8}$ Cf. Miller (1997), Campbell (2001), Slater (2001), McCraken (2003) e Appadurai (2008).

${ }^{9}$ A expressão "paradigma da dávida" é de Caillé (1998).
} 
As motivações da dádiva, diz ele, não podem ser confinadas no interesse material ou econômico, mas também não podem ser explicadas por puro altruísmo e desprendimento. Há outros interesses, lembra Caillé (1998), além daqueles estritamente econômicos ou materiais, já que o próprio Mauss (2003, p. 306) afirmava a existência do desejo de ser "o mais belo, o primeiro, o mais sortudo, o mais forte", além do mais rico. Interesses de glória, fama ou boa reputação podem ser, em certos casos, priorizados em relação aos ganhos (e interesses) econômicos.

Assim, a dádiva seria percebida como uma espécie de aposta - na aliança e na confiança - e uma abertura quanto à incerteza do retorno. Ela seria ao mesmo tempo livre e obrigada. Como sugere Lanna (2000), a dádiva é uma superação relativa de uma dualidade profunda do pensamento ocidental entre espontaneidade e obrigatoriedade, interesse e altruísmo, egoísmo e solidariedade.

O paradigma da dádiva, assim, reflete a complexidade e a multiplicidade de determinantes presentes na vida social. Podemos pensar, entretanto, que nem a dádiva é total desinteresse e altruísmo, nem o mercado é todo racionalidade instrumental, já que a multiplicidade de determinantes também é encontrada nas trocas comerciais monetarizadas.

É bem verdade que, no grupo estudado, a maioria das trocas comerciais é monetarizada. Ainda que ali bens sejam trocados por dinheiro, insistimos que essa não seja a única dimensão da troca. Em primeiro lugar, sublinhamos que os procedimentos de compra e venda estabelecidos na plataforma Mercado Livre possuem forte dimensão de aposta. Distante no espaço físico/ geográfico, um par de trocadores precisará optar quem apostará, definindo se primeiro o produto será enviado pelo vendedor ou pago pelo comprador. Em geral, é costume que primeiro o produto seja pago, através de depósito bancário, e depois enviado. Assim, dinheiro é trocado por um bem, mas há um tempo de incerteza cuja (boa) finalização dependerá apenas da conduta do outro parceiro.

Podemos pensar que, além de produtos, as qualificações são outra dimensão de "coisas trocadas". E já que a reputação, fundada nas qualificações, é a única garantia que pode oferecer um vendedor/comprador, esta dimensão não pode ser menosprezada. Assim, ao cumprir sua parte no acordo, realizando o pagamento de maneira adequada e no tempo estipulado, um consumidor receberá o produto e igualmente uma boa qualificação por parte do vendedor. 0 vendedor, por sua vez, enviando o produto prometido, terá recebido em troca dele a quantia de dinheiro acordada e uma boa qualificação. Se qualquer um dos termos do par romper o acordo estabelecido na troca, receberá uma qualificação negativa.

Mesmo no caso de trocas que não se repetem, nas quais cada transação específica tem fim quando os dois interessados escrevem as qualificações, não se pode falar de uma relação que começa e termina no produto trocado e no dinheiro recebido. As palavras expressas na qualificação, marcando a reputação de ambos no grupo, permanecerão e servirão de parâmetro para o estabelecimento (ou não) de futuras trocas comerciais com futuros parceiros.

\section{A POLARIZAÇÃO DÁDIVA VERSUS MERCADORIA}

É preciso ressaltar que a discussão sobre troca versus comércio esteve balizada, na Antropologia, pela oposição entre gift (dádiva, dom, presente) e commodity (mercadoria), como se não apenas a relação social estabelecida através da troca, mas os próprios objetos trocados fundassem a polaridade. De acordo com Jerry Leach (1983), Malinowski e Mauss acreditavam que o valor simbólico desses objetos, expresso em sua troca, era totalmente distinto de um valor econômico-utilitário, típicos da mercadoria. Para o primeiro, ainda de acordo com Leach, o Kula 
se apresentava como um fim em si mesmo, trazendo aos parceiros de troca uma recompensa mais emocional do que econômica ou política.

Firth (1983), entretanto, propondo a superação do exagerado grau de separação entre essas esferas, sugere que o Kula seja também visto como um conjunto de relações macroeconômicas. Nesse sentido, ele está interessado em compreender os mecanismos que permitem que valor e preço sejam estabelecidos e mantidos. Para o autor, os critérios materiais seriam relevantes, já que os objetos trocados no Kula são duráveis e específicos, e "Se comparado com muitas transações de troca da Oceania, o Kula envolve o foco estrito num objeto individual e específico (um determinado bracelete ou determinado colar), e não - como entre os Tikopia no fato de que algum bracelete ou algum colar troca de mãos". (FIRTH, 1983, p. 90).

Sem desconsiderar a importância da discussão de Firth sobre os mecanismos de atribuição de preço, Edmund Leach (1983), entretanto, argumenta que o mesmo e idêntico objeto poderá estar engajado em mais de um desses mecanismos, possuindo um valor específico quando estiver participando como peça do "jogo" do Kula e outro valor distinto quando está sendo utilizado numa forma de troca não-Kula.

A ponderação de Edmund Leach parte da análise de Damon $(1983,2002)$ sobre os kitoum, objetos Kula em circulação temporariamente retirados do fluxo de troca por seu dono temporário, com o objetivo de pagar uma dívida privada fora do circuito Kula. Se, posteriormente, adverte o autor, o sujeito em questão recebe em alguma outra transação comercial outro objeto do tipo do Kula, pode recolocá-lo no sistema no mesmo lugar onde, por ter retirado um colar ou um bracelete, o sistema fora interrompido.

Damon (1983), sublinhando o fato que os mesmos objetos são acionados em diferentes tipos de transações e mostrando que são dotados, em cada uma, de um tipo de valor diverso, antecipa, em alguma medida, a discussão que seria aprofundada posteriormente por Appadurai (2008).

Appadurai (2008) aponta o contraste frequentemente atribuído ao par dádiva versus mercadoria. Segundo o autor, ao passo que a dádiva remete à noção de reciprocidade, sociabilidade e espontaneidade, a mercadoria teria ficado marcada, nas Ciências Sociais, pela imagem da troca a-social, permeada pela ganância, pelo cálculo econômico e pelo individualismo. Ela seria filha do dinheiro e não da sociabilidade. Podemos pensar que essa visão representa outra oposição - aquela entre as ditas sociedades "tradicionais" e as "sociedades complexas", orquestrando um dualismo nós versus eles.

A sugestão de Appadurai é de que podemos romper com tal dualismo partindo do pressuposto de que as coisas não são mercadorias ou dádivas, mas estão mercadorias ou dádivas. Como mostra Kopytoff (2008, p. 89), as coisas entram e saem do estado mercantil, e seu estado enquanto mercadoria é apenas uma fase de sua vida social:

Do ponto de vista cultural, a produção de mercadorias é também um processo cognitivo e cultural: as mercadorias devem ser não apenas produzidas materialmente como coisas, mas também culturalmente sinalizadas como um determinado tipo de coisas. Do total de coisas disponíveis numa sociedade, apenas algumas são apropriadamente sinalizáveis como mercadorias. Alem do mais, a mesma coisa pode ser tratada como uma mercadoria numa determinada ocasião, e não ser em outra. Finalmente, a mesma coisa pode, ao mesmo tempo, ser vista por uma pessoa como uma mercadoria, e como uma outra coisa por outra pessoa. 
Assim, o estatuto de um bem enquanto mercadoria ou enquanto dádiva e, como consequência, a determinação de seu valor ou preço, dependeria dos padrões de valores específicos compartilhados, aquilo que Appadurai (2008) chama de "diferentes regimes de valor". Circulando por diversos regimes de valor, objetos de todos os tipos poderiam tomar variadas rotas e desvios, tornando-se mercadoria, deixando de sê-lo, e podendo, inclusive, retornar posteriormente ao estado mercantil.

\section{DO CONSUMIDOR AO COLECIONADOR}

Dentre as categorias de produtos comercializados ou trocados via Mercado Livre, um espaço significativo é ocupado pela compra e venda de produtos usados (artigos de vestuário, decoração, livros, antiguidades, entre outros). As considerações sobre o "estado do produto" fazem parte das preocupações de vendedores e compradores, mas as narrativas sobre a história e trajetória dos mesmos também compõem grande parte dos anúncios.

Atuando no ramo dos produtos usados, no Mercado Livre, há uma grande presença de colecionadores, cujas coleções vão de selos a carros antigos - passando por obras de arte, abridores de garrafa, brinquedos, moedas, chapéus, caixas de fósforo etc. - que usam o espaço para adquirir ou revender objetos colecionados. E se o consumo, na contemporaneidade, está quase sempre associado ao descarte, há, no caso estudado, um padrão diferenciado, no qual objetos usados retornam, entrando novamente em circulação.

No caso dos objetos de segunda mão, vemos retornando ao mercado bens que, quando de sua produção, eram encarados como "mercadorias terminais": aquelas fabricadas para circular uma única vez, percorrendo apenas a rota produção-distribuição-consumo. No que concerne, por exemplo, às coleções de brinquedos usados, de selos, de latinhas de refrigerante vazias ou de antiguidades, os desvios de rota podem ser claramente identificados, assim como a ressignificação desses objetos quando atravessam os diferentes regimes de valor.

Tratando especificamente do colecionismo, Abbas (1988) sugere que a prática envolve um ato de consumo, mas igualmente uma atividade antimaterialista, configurando uma espécie de desmercantilização da coisa adquirida e incorporada numa coleção. Quando um objeto entra em uma coleção, seu valor deixaria de ser apenas aquele de mercado. Ele se singulariza com relação aos seus semelhantes, circulando no mercado e, ao mesmo tempo, adquire seu novo valor em relação ao conjunto maior da coleção da qual faz parte. Enfatizando a importância da coleção enquanto conjunto, Belk (1998, p.67) define o colecionismo como "processo ativo, seletivo e apaixonado de adquirir e possuir coisas removidas de seu uso ordinário e percebidas como parte num conjunto de objetos ou experiências não idênticos".

De acordo com Belk (2008), os colecionadores são, frequentemente, representados como pertencendo a duas categorias de pessoas aparentemente antagônicas. De um lado, teríamos a representação do colecionador como consumidor egoísta e sempre ávido por comprar mais. De outro, a imagem do colecionador como uma espécie de herói romântico que salva os objetos de seu uso ordinário e utilitário, dando-Ihes um lugar seguro. Assim, os objetos colecionados são ao mesmo tempo consumidos e acumulados, e o ato de colecionar evoca a ideia da preservação.

Normalmente não há ganhos financeiros diretamente envolvidos no colecionismo, mas, de acordo com Gelber (1992), muitos colecionadores buscam uma racionalização de sua prática através da elaboração de discursos que situam a coleção como um investimento. Mesmo que a maioria deles não cogite a ideia de desfazer-se dos objetos colecionados, já que estes se tornam "mercadorias sem preço", justificam a coleção como uma possibilidade de recompensa financeira futura. 
Como mostram Ellis e Haywood (2006), colecionar envolve um processo de seleção e classificação, gerando um tipo de consumo que é permeado por planejamento em longo prazo. Mas, ainda que envolva planejamento, outro aspecto presente na prática do colecionismo é a noção de que o bom colecionador é aquele que é capaz de balancear seus conhecimentos acumulados sobre o tipo de coisa colecionada com certa dose de paciência e de sorte. Boas aquisições devem ser garimpadas, razão pela qual paciência e conhecimento se fazem necessários, mas o acaso e sorte também são vistos como fatores de grande importância.

$\mathrm{O}$ ato de "garimpar", que caracteriza a prática do colecionismo, em muito aproxima o colecionador do consumidor, ao que Campbell (2005) define como craft consumer. Esse tipo de consumidor, de acordo com o autor, não é o consumidor de produto artesanal (ainda que, por vezes, também possa ser esse seu tipo de produto favorito), e sim o sujeito para o qual o ato de consumir é artesanal, envolvendo nuanças de elaboração criativa, transformando mercadorias em objetos personalizados. Seu consumo, mesmo quando os bens consumidos são originários de produção industrial e massificada, poderá envolver tanto escolhas minuciosas e pesquisadas - o "garimpar" - quanto um tipo de aprendizado, originado da busca de informação.

Essas informações, que Appadurai (2008) vai chamar de "mitologias", terminam por ser tão atrativas e consumíveis quanto os objetos. As mitologias que acompanham os bens de consumo são identificadas por Appadurai como sendo de três variedades: ${ }^{10}$ aquelas produzidas por seus distribuidores e revendedores; aquelas produzidas por seus consumidores ou consumidores em potencial; e aquelas produzidas pelos produtores.

Como diversos autores que se dedicam a refletir sobre o consumo apontam, ${ }^{11}$ os bens, ainda que fruto da imaginação e do esforço humano, não saem já da linha de montagem carregando consigo sentidos culturais prontos. Os significados não são intrínsecos aos objetos e tampouco se encontram completamente constituídos durante o processo de produção. Assim, as histórias e informações que acompanham os bens colecionados podem ser vistos como fornecedor em potencial de "material de sonho" a ser empregado naquilo que Campbell (2001, p. 130) chama de prazer imaginativo do consumidor moderno: "a atividade fundamental do consumo [...] não é a verdadeira seleção, a compra, o uso dos produtos, mas a procura do prazer imaginativo a que a imagem do produto se empresta".

A raridade do objeto e sua singularidade são elementos citados como fundamentais pelos colecionadores, tanto em suas narrativas enquanto consumidores quanto naquelas elaboradas quando se colocam como vendedores. Nesse último caso, a indicação "único no Mercado Livre" acompanha o anúncio do produto e, se o item é realmente raro e valorizado entre o grupo de colecionadores, diversos elogios são tecidos por outros usuários na parte do anúncio dedicada às perguntas de compradores.

Como parte das mitologias, também verificamos a presença de uma série de informações apresentadas pelos vendedores dos produtos anunciados. Algumas dessas informações dizem respeito à história do item e de sua obtenção, como no caso de um tijolo antigo, anunciado pelo vendedor como tendo sido "encontrado em uma fazenda do ciclo do café nas imediações da cidade Campinas. Acompanha recorte de jornal da época da descoberta". A narrativa sobre a obtenção do item confere autenticidade ao objeto e ao vendedor.

\footnotetext{
10 Pode-se ver uma transposição da tipologia proposta por Appadurai, aplicada à risca, para a análise de dados etnográficos no trabalho de Skoggard (1998) a respeito do consumo de sapatos esportivos made in Taiwan no Norte da África.

${ }^{11}$ Cf. Douglas e Isherwood, (2004) e Miller (2002).
} 
Além da procedência do objeto colecionável, relatos sobre seus antigos donos são também costumeiros, sobretudo quando se trata de um proprietário famoso. É o que vemos, por exemplo, no caso de um prato alemão de porcelana, fabricado em 1914, que, de acordo com o vendedor, "pertenceu ao serviço de porcelanas da Duquesa Sofia Hohenberg, documentados nos carimbos do fabricante" e cuja data de fabricação coincidiria com o "centenário da fundação da fábrica [de porcelanas], data fatídica para a Duquesa, assassinada no mesmo ano". O anúncio traz mais alguns dados biográficos da antiga proprietária, enfatizando, é claro, sua trágica morte ao lado do marido.

Mas se o significado do objeto colecionado é construído a partir das "mitologias" que o acompanham em sua trajetória, a própria identidade do colecionador - enquanto colecionador e enquanto colecionador de uma determinada categoria específica de coisas - será construída por meio desses objetos, seja por sua posse ou desejo de posse.

Munn (1983, p. 283), tratando dos mecanismos de definição de valor presentes no Kula, parece apontar na mesma direção quando sublinha o duplo movimento executado pelos homens e por suas conchas:

Embora os homens pareçam ser os agentes na definição do valor das conchas, sem conchas eles não podem definir seu próprio valor; quanto a isso, conchas e homens são agentes recíprocos na definição do valor de um e de outro.

À semelhança das conchas, os itens colecionados (possuídos, vendidos, consumidos, trocados) são objetos que atuam na construção de identidades e de memórias. Nesse sentido, um colecionador de caixas de fósforo relata que é o tamanho de sua coleção (7.234 caixinhas em outubro de 2009) que faz dele um verdadeiro filamenista. Mais do que o número, entretanto, importa-lhe remeter algumas delas a sua trajetória e memória: uma caixa de fósforos adquirida recentemente, mas produzida para a Copa do Mundo de 1962, lembra-lhe a adolescência, fazendoo "ficar pensando no que fazia e nos amigos que tinha naquele ano"; outra, obtida por ele mesmo em um voo da VASP, "há algumas décadas, na época em que se fumava em avião", trazemIhe recordações de uma viagem e da namorada que o acompanhava. Assim, se os colecionadores, através de suas compras, vendas e trocas, transformam os objetos de mercadorias em peças colecionadas, a própria identidade do colecionador é, nesse processo, construída na e pela prática do colecionismo.

\section{CONSIDERAÇÕES FINAIS}

Analisamos aqui uma modalidade de troca comercial realizada na Internet que se enquadra naquilo que, atualmente, convencionou-se chamar de comércio P2P. Tal tipo de transação comercial, por definição, seria estabelecido entre parceiros idealmente equivalentes, de pessoa para pessoa. A partir desta experiência de pesquisa foi possível observar que as relações sociais que têm lugar na plataforma Mercado Livre não se restringem à circulação de dinheiro ou mercadorias. A troca de informações, tanto sobre bens quanto sobre parceiros em potencial, ocupa lugar importante entre os usuários. Além disso, mostraram-se bastante frequente as trocas que se repetem, entre sujeitos já conhecidos anteriormente.

A centralidade dos laços firmados com outros usuários, acrescida do grande valor depositado na honra, na reputação e na confiança mútua, permitem refletir sobre a oposição entre comércio e troca não comercial. Uma série de características comumente atribuídas ao 
mercado e ao comércio, como a impessoalidade, o anonimato e a instrumentalidade, são, em alguma medida, colocadas em xeque. Assim, retomando a discussão sobre dádiva e mercadoria na teoria antropológica, concordamos com a noção de que uma e outra não são polos opostos e fechados, e sim possíveis fases ou momentos de sua trajetória.

Os objetos não são dádivas ou mercadorias, mas estão dádivas ou mercadorias a tal definição depende de sua circulação por diferentes regimes de valor. Nesse sentido, colecionismo, prática a qual se dedicam parte significativa dos usuários do site Mercado Livre, é exemplar para que pensemos sobre as idas e vindas das "coisas" ao longo de sua biografia social. Entrando e saindo do estado de "bem de consumo", os produtos comprados, vendidos e colecionados encontram-se envoltos em mitologias que the conferem identidades.

Mais além, como sugerimos, atuam no mundo social de maneira a colaborar para construções identitárias daqueles por cujas mãos circulam. As relações sociais estabelecidas entre usuários da plataforma Mercado Livre, especialmente no caso dos colecionadores, são, portanto, lugar privilegiado para a compreensão da interação entre sujeitos e objetos e entre sujeitos mediada por objetos.

\section{REFERÊNCIAS BIBLIOGRÁFICAS}

ABBAS, A. Walter Benjamin's collector: the fate of modern experience. New Literary History, n. 20, 1998. p. 216-236.

APPADURAI, A. Introdução: mercadorias e a política de valor. In: (Org.). A vida social das coisas. Niterói: EDUFF, 2008. p. 15-88.

BELK, R. The double nature of collecting. Etnofoor, n. 11, v. 1, p. 7-20, 1998.

. Collectors and collecting. In: TILLEY, C. et al. (Ed.). Handbook of material culture. Londres: Sage, 2008. p. 534-545.

BLOCH, M. Les usages de l'argent. Terrain, n. 23, p. 5-10, out. 1994.

BRAUDEL, F. Civilização material, economia e capitalismo. v. 2: O jogo das trocas. São Paulo: Martins Fontes, 1996.

CAILLÉ, A. Nem holismo, nem individualismo metodológico: Marcel Mauss e o paradigma da dádiva. Revista Brasileira de Ciências Sociais, v. 13, n. 38, p. 5-37, 1998.

CAMPBELL, C. A ética romântica e o espírito do consumismo moderno. Rio de Janeiro: Rocco, 2001. . The craft consumer. Journal of Consumer Culture, Londres, v.5, n.1, p. 23-42, 2005.

CASTELLS, M. A galaxia da Internet: reflexões sobre a Internet, os negócios e a sociedade. Rio de Janeiro: Zahar, 2003.

COMITÊ GESTOR DA INTERNET NO BRASIL. Pesquisa sobre o Uso das Tecnologias da Informação e da Comunicação no Brasil. Março de 2009. Disponível em: <http://www.cetic.br/palestras/pdf/2008/pal2008conip-06.pdf>. Acesso em: 20 jul. 2009. 
DAMON, F. What moves the kula: opening and closing gifts on Woodlark Island. In: LEACH, J; LEACH, E. (Ed.). The kula: new perspectives on massim exchange. Cambridge: Cambridge University Press, 1983. p. 309-344.

Kula valuables: the problem of value and the production of names. L'Homme, n. 162, 2002. p. 107

136.

DOUGLAS, M.; ISHERWOOD, B. O mundo dos bens: para uma antropologia do consumo. Rio de Janeiro: Ed. da UFRJ, 2004.

ELLIS, R; HAYWOOD, A. Virtual radiophile (163): eBray and the changing collecting practices of the U.K. vintage radio community. In: HILLS, K; PETIT, M; EPLAY, N. Everyday Ebay: culture, collecting and desire. Nova lorque: Routledge, 2006. p. 45-62.

FIRTH, R. Magnitudes and values in kula exchange. In: LEACH, J; LEACH, E. (Ed). The Kula: new perspectives on massim exchange. Cambridge: Cambridge University Press, 1983. p. 89-102.

GELBER, S. Free market mataphor: the historical dynamics of stamp collecting. Comparative Studies in Society and History, n. 34, p. 742-769, 1992.

GETSCHKO, D. Internet, mudança ou transformação?. In: COMITÊ GESTOR DA INTERNET NO BRASIL. Pesquisa sobre o uso das tecnologias da informação e da comunicação 2008. São Paulo: CETIC, 2009.p. 49-52, 2009.

GODBOUT, J. T. Introdução à dádiva. Revista Brasileira de Ciências Sociais, n. 38, v. 13, p. 39-51,1998.

HART, K. Money in a unequal world. Londres: Texere, 2001.

Notes towards as anthropology of internet. Horizontes Antropológicos, n. 21, 2004. p. 15-40.

IBGE. Instituto Brasileiro de Geografia e Estatística. Pesquisa Nacional por amostra de domicílios: acesso à internet e posse de telefone móvel celular para uso pessoal. 2005. Disponível em: <http://www.ibge.gov.br/ home/estatistica/populacao/acessoainternet/ internet.pdf>. Acesso em: 20 jul. 2009.

KOPYTOFF, I. A biografia cultural das coisas: a mercantilização como processo. In: APPADURAI, A. A vida social das coisas. Niterói: EDUFF, 2008. p. 89-124.

LANNA, M. Notas sobre Marcel Mauss e o ensaio sobre a dádiva. Revista de Sociologia e Política, v. 4, 2000. p. 173-193.

LEACH, E. The kula: an alternative view. In: LEACH, J; LEACH, E. (Ed.). The Kula: new perspectives on massim exchange. Cambridge: Cambridge University Press, 1983. p. 529-538.

LEACH, J. Introduction. In: LEACH, J; LEACH, E. (Ed.). The Kula: new perspectives on massim exchange. Cambridge: Cambridge University Press, 1983. p. 1-28.

LÈVY, P. A conexão planetária: o mercado, o ciberespaço, a consciência. São Paulo: Editora 34, 2001.

LINS RIBEIRO, G. Internet e a emergência da comunidade imaginada transnacional. Revista Sociedade e Estado, v. 10, 1995. p. 181-191.

MALINOWSKI, B. Argonautas do pacífico ocidental. São Paulo: Abril Cultural, 1978.

MAUSS, M. Ensaio sobre a dádiva. In Sociologia e Antropologia. São Paulo: Cosac Naify, 2003. p. 183314.

McCRAKEN, G. Cultura \& consumo. Rio de Janeiro: Mauad, 2003.4 
MILLER, D. Capitalism: an ethnographic approach. Oxford: Berg, 1997. . Teoria das compras. São Paulo: Livraria Nobel, 2002.

MONJARET, A. L’argent des cadeaux. Ethnologie Française, XXVIII, 1998. p. 493-505.

MUNN, N. Gawan kula: spatiotemporal control and the symnolism of influence. In: LEACH, J; LEACH, E. (Ed.). The Kula: new perspectives on massim exchange. Cambridge: Cambridge University Press, 1983. p. 277-308.

OLIVEN, R. De olho no dinheiro nos Estados Unidos. Estudos Históricos, n. 27, 2001. 206-235, 1997.

O vil metal: o dinheiro na música popular brasileira. Revista Brasileira de Ciências Sociais, v. 33, p. Consumo, logo existo. In: LEITÃO, D; MACHADO, R.; LIMA, D. Antropologia e consumo. Porto Alegre: AGE, 2006. p. 7-8.

POLANYI, K. A grande transformação. Rio de Janeiro: Elsevier, 2000.

SAHLINS, M. La pensée bourgeoise. In Cultura e razão prática. Rio de Janeiro: Zahar, 2003. p. 166-203.

SIGAUD, L. As vicissitudes do “Ensaio sobre o Dom”. Mana, v. 5, p. 89-124, 1999.

SIMMEL, G. A metrópole e a vida mental. In: VELHO, O. (Org.). O fenômeno urbano. Rio de Janeiro: Zahar, 1979. p. 11-25.

The philosophy of money. London: Routledge, 2004.

SKOGGARD, I. Transnational commodity flows and the global phenomenon of brand. In: BRYDON, A; NIESSE, S. (Ed.). Consuming fashion: adorning the transnational body. Oxford: Berg, 1998. p. 57-70.

SLATER, D. Cultura do consumo e modernidade. São Paulo: Livraria Nobel, 2001.

ZELIZER, V. The social meaning of money. Princeton: Princeton University Press, 1997.

. Repenser le marché. Actes de la Recherche en Sciences Sociales, n. 94, p. 3-26, 1992. 